\title{
Employment grade and coronary heart disease in British civil servants
}

\author{
M. G. MARMOT, GEOFFREY ROSE, M. SHIPLEY, AND P. J. S. HAMILTON \\ From the Department of Medical Statistics and Epidemiology, London School of Hygiene and Tropical Medicine
}

SUMMARY The relationship between grade of employment, coronary risk factors, and coronary heart disease (CHD) mortality has been investigated in a longitudinal study of 17530 civil servants working in London. After seven and a half years of follow-up there was a clear inverse relationship between grade of employment and CHD mortality. Men in the lowest grade (messengers) had 3.6 times the CHD mortality of men in the highest employment grade (administrators). Men in the lower employment grades were shorter, heavier for their height, had higher blood pressure, higher plasma glucose, smoked more, and reported less leisure-time physical activity than men in the higher grades. Yet when allowance was made for the influence on mortality of all of these factors plus plasma cholesterol, the inverse association between grade of employment and CHD mortality was still strong. It is concluded that the higher CHD mortality experienced by working class men, which is present also in national statistics, can be only partly explained by the established coronary risk factors.

A striking feature of the British mortality statistics is that death from coronary heart disease (CHD) is now more common in working class men and women than in those of higher status (Registrar General, 1978). Such vital statistical data have been useful in pointing to occupational groups possibly at high risk. They do not, however, suggest reasons for the class gradient in disease. To identify and, if possible, explain any social class gradient in CHD mortality in a group of employed men, data were analysed from the Whitehall study of civil servants (Reid et al., 1974).

The Whitehall study was initiated by Professor Reid. It was based on a survey of male civil servants working in London who were examined between 1967 and 1969, and whose subsequent mortality has been followed (Reid et al., 1976; Rose et al., 1977a). The present paper reports CHD mortality in seven and a half years of follow-up for men employed in different grades. The association between employment grade, CHD mortality, and the major coronary risk factors is then examined.

\section{Methods}

18403 men attended the initial screening examination. Each man received a standardised questionnaire which, among other items, asked for his grade of employment. Men were then classified into administrative, professional, executive, clerical, and 'other' grades. The 'other' grade was the lowest in status, and included mainly messengers and other unskilled manual workers. Excluded from this analysis were 873 men from the Diplomatic Service and the British Council, among whom the classification of employment status was not comparable. Thus the present analysis is confined to 17530 men from other departments.

The initial examination included the London School of Hygiene Cardiovascular Questionnaire (Rose et al., 1977b) and standardised questions on smoking history, respiratory symptoms, medical treatment, and leisure-time activities. Electrocardiograms were classified according to the Minnesota Code (Rose and Blackburn, 1968), and blood pressure, plasma cholesterol, blood glucose, height, and weight were determined in standardised fashion (Reid et al., 1974).

For over $99 \%$ of the subjects, their records in the Central Registry of the National Health Service were identified and tagged, and a copy of the death certificate has been provided for each subject who has since died within the United Kingdom. Mortality follow-up is now complete for seven and a half years. There have been 1086 deaths in this period, of which 462 were assigned to CHD (ICD codes 410-414) (World Health Organisation, 1967). Death certificates were coded by the Office of Population Censuses and Surveys. 
Adjustment for age was carried out by the direct method, using the total population as the standard. Where the age-adjusted rates were further adjusted for the distribution of another risk factor, this was similarly carried out by the direct method. The multivariate analysis made use of the multiple logistic equation, which also yielded estimates of the extent to which differences in risk between grades were attributable to the independent effect of each risk factor. This was done by calculating the relative increase in risk expected from a given increase in, say, blood pressure, taking the risk of the top (administrative) grade as 1.0. The magnitude of the difference in risk factor used in this calculation was equal to the difference in the means between the administrative grade and each of the grades below.

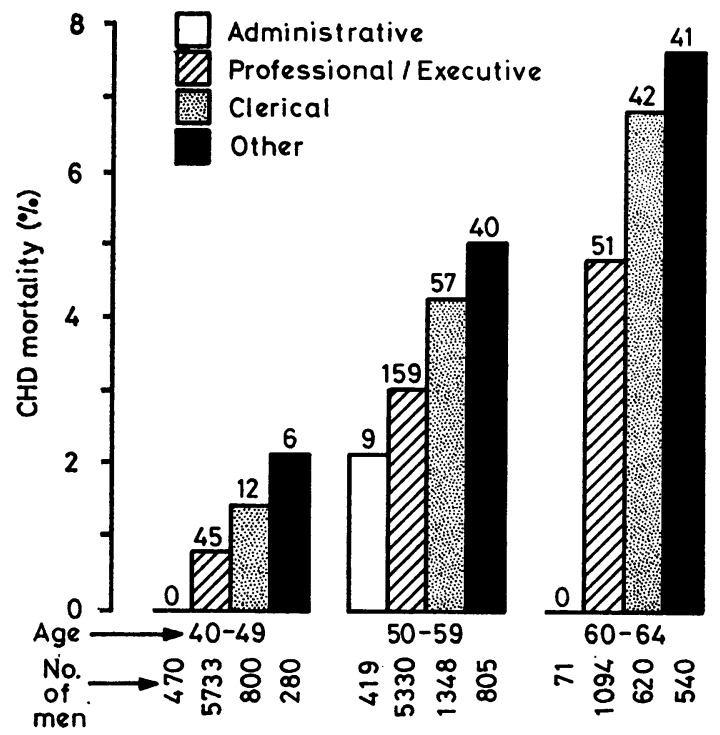

Fig. 1 Coronary heart disease mortality (and number of deaths) in seven and a half years by civil service grade and age.

The figures on top of the histograms are the numbers of $\mathrm{CHD}$ deaths.

\section{Results}

\section{GRADE AND CHD MORTALITY}

Figure 1 presents the mortality from CHD in each grade and age group over the seven and a half years of follow-up. There was no a priori reason for ranking professional and executive grades differently, and their CHD death rates were in fact identical; the results for these two grades have therefore been pooled throughout the analysis.
Within each age group, there is a regular stepwise relationship between grade of employment and risk of CHD death; the lower the grade, the higher the risk. Overall, the men in the lowest ('other') grade had 3.6 times the CHD mortality rate of the men in the highest (administrative) grade.

\section{GRADE AND OTHER RISK FACTORS}

To explain this large difference in CHD mortality, it is necessary to analyse the age-adjusted distribution of coronary risk factors in the different grades (Table 1). It can be seen that systolic blood pressure shows a clear negative association with grade, whether expressed as mean blood pressure or as per cent of men having a value $\geqslant 160 \mathrm{mmHg}$. By contrast, for plasma cholesterol the gradient is in the other direction: the higher the grade, the higher the plasma cholesterol.

The proportion of current cigarette smokers was more than twice as high in the 'other' grade (60.9\%) as it was among administrators $(28 \cdot 8 \%)$. There was little difference between the grades in the mean of body mass index, but the distribution was different: in the lower grades more men were heavy for their height and more were light for their height.

At the initial examination men were questioned briefly about their leisure-time activities, and these have been classified as 'inactive', 'moderately active', or 'active'. More of the upper grade men reported 'active' leisure-time pursuits. This may be especially relevant, since none of these men was employed in a physically demanding job.

There was also a striking positive association between grade and height. Men in the 'other' grade were on average more than five centimetres shorter than men in the administrative grade. More than $20 \%$ of administrators were over six feet tall, but fewer than $10 \%$ of men in the bottom grade.

Height is presented here because in this population shorter men have a higher CHD mortality (Table 2). In multivariate analysis, this association is independent of other coronary risk factors, including grade.

\section{GRADE, CHD MORTALITY, AND CORONARY RISK FACTORS}

The next step in the analysis was to assess the extent to which differences between the grades in these risk factors might account for the grade differences in CHD mortality. Figure 2 presents the age-adjusted CHD mortality rates in each grade, in relation to blood pressure, plasma cholesterol, smoking, and height. Adjustment for smoking and for height slightly reduced the relative differences in CHD mortality between the highest and lowest grades. Adjustment for blood glucose, 
Table 1 Major risk factors in different grades: age-adjusted means and per cent showing 'elevated' values

\begin{tabular}{|c|c|c|c|c|}
\hline \multirow[b]{2}{*}{ Variable } & \multicolumn{4}{|l|}{ Grade } \\
\hline & Administrative & $\begin{array}{l}\text { Professionall } \\
\text { Executive }\end{array}$ & Clerical & Other \\
\hline $\begin{array}{l}\text { SYSTOLIC BP } \\
\text { Mean } \pm \text { SEM } \\
\text { Per cent } \geqslant 160\end{array}$ & $\begin{array}{l}133 \cdot 7 \pm 0 \cdot 67 \\
10 \cdot 7\end{array}$ & $\begin{array}{l}136 \cdot 0 \pm 0 \cdot 19 \\
12 \cdot 2\end{array}$ & $\begin{array}{l}136 \cdot 8 \pm 0 \cdot 42 \\
13 \cdot 8\end{array}$ & $\begin{array}{l}137 \cdot 9 \pm 0 \cdot 64 \\
16 \cdot 5\end{array}$ \\
\hline $\begin{array}{l}\text { PLASMA CHOLESTEROL } \\
\text { Mean } \pm \text { SEM } \\
\text { Per cent } \geqslant 260 \mathrm{mg} \%\end{array}$ & $\begin{array}{l}201 \cdot 0 \pm 1 \cdot 72 \\
12 \cdot 6\end{array}$ & $\begin{array}{l}198 \cdot 7 \pm 0 \cdot 44 \\
10 \cdot 2\end{array}$ & $\begin{array}{l}196 \cdot 6 \pm 1 \cdot 00 \\
10 \cdot 5\end{array}$ & $\begin{array}{l}192 \cdot 0 \pm 1 \cdot 47 \\
7 \cdot 8\end{array}$ \\
\hline $\begin{array}{l}\text { SMOKING } \\
\text { Per cent smokers } \\
\text { Never smoked } \\
\text { Ex-smokers }\end{array}$ & $\begin{array}{l}28 \cdot 8 \\
33 \cdot 0 \\
38 \cdot 1\end{array}$ & $\begin{array}{l}37 \cdot 3 \\
23 \cdot 2 \\
39 \cdot 6\end{array}$ & $\begin{array}{l}53.0 \\
17.0 \\
29.9\end{array}$ & $\begin{array}{l}60 \cdot 9 \\
14 \cdot 8 \\
24 \cdot 3\end{array}$ \\
\hline $\begin{array}{l}\left.\text { BMI (WEIGHT/HEIGHT }{ }^{2}\right) \\
\text { Mean } \pm \text { SEM } \\
\text { Per cent } \geqslant 28\end{array}$ & $\begin{array}{c}24.5 \\
9.9\end{array}$ & $\begin{array}{l}24.8 \pm 0.03 \\
11.8\end{array}$ & $\begin{array}{l}24 \cdot 6 \pm 0 \cdot 07 \\
13 \cdot 8\end{array}$ & $\begin{array}{l}25 \cdot 0 \pm 0 \cdot 10 \\
17 \cdot 4\end{array}$ \\
\hline $\begin{array}{l}\text { BLOOD GLUCOSE* } \\
(2 \text { hour post load) } \\
\text { Mean } \pm \text { SEM } \\
\text { Per cent } \geqslant 90 \mathrm{mg} \% \\
\text { Per cent diabetic }\end{array}$ & $\begin{array}{l}75 \cdot 1 \pm 0 \cdot 47 \\
10 \cdot 1 \pm 0 \cdot 47 \\
1 \cdot 3\end{array}$ & $\begin{array}{l}75 \cdot 3 \pm 0 \cdot 16 \\
9.7 \\
0.7\end{array}$ & $\begin{array}{l}76 \cdot 7 \pm 0 \cdot 40 \\
12 \cdot 1 \\
1 \cdot 4\end{array}$ & $\begin{array}{l}77 \cdot 5 \pm 0 \cdot 82 \\
13 \cdot 1 \\
1 \cdot 1\end{array}$ \\
\hline $\begin{array}{l}\text { PHYSICAL ACTIVITY } \\
\text { Per cent inactive } \\
\text { Per cent moderately active } \\
\text { Per cent active }\end{array}$ & $\begin{array}{l}26 \cdot 3 \\
36 \cdot 8 \\
36 \cdot 8\end{array}$ & $\begin{array}{l}29 \cdot 5 \\
45 \cdot 3 \\
25 \cdot 2\end{array}$ & $\begin{array}{l}43 \cdot 0 \\
36 \cdot 3 \\
20 \cdot 7\end{array}$ & $\begin{array}{l}56 \cdot 0 \\
30.0 \\
14.0\end{array}$ \\
\hline $\begin{array}{l}\text { HEIGHT } \\
\text { Mean } \pm \text { SEM } \\
\text { Per cent } \geqslant 183 \mathrm{~cm}(6 \mathrm{ft})\end{array}$ & $\begin{array}{c}178 \cdot 5 \pm 0 \cdot 20 \\
21 \cdot 1\end{array}$ & $\begin{array}{c}176.3 \\
12.8\end{array}$ & $\begin{array}{c}174 \cdot 0 \pm 0 \cdot 13 \\
7 \cdot 6\end{array}$ & $\begin{array}{r}173 \cdot 2 \pm 0 \cdot 23 \\
8 \cdot 7\end{array}$ \\
\hline
\end{tabular}

Excluding diabetics.

Table 2 CHD mortality in seven and a half years according to height (age-adjusted)

\begin{tabular}{llll}
\hline & \multicolumn{3}{c}{ CHD death } \\
\cline { 3 - 4 } Height & $N$ & No. & (Age-adjusted) \\
\hline$\leq 5^{\prime} 6^{\prime \prime}$ & 2290 & 103 & $3 \cdot 7$ \\
$=5^{\prime} 9^{\prime \prime}$ & 6672 & 172 & $2 \cdot 5$ \\
$-6^{\prime} 0^{\prime \prime}$ & 6433 & 144 & $2 \cdot 4$ \\
$>6^{\prime} 0^{\prime \prime}$ & 2132 & 43 & $2 \cdot 4$ \\
\hline
\end{tabular}

body mass index, and reported physical activity had little impact on the grade differences in mortality.

To assess the combined effect of adjustment for these risk factors a multivariate analysis was used. In Figure 3, the risk of the administrators is taken as 1.0. The relative risks of the professional and executive, the clerical, and the 'other' grades were then $2 \cdot 1,3 \cdot 2$, and 4.0 respectively. (These estimates of relative risk differ very slightly from those in Figure 1, because here the adjustment for age was carried out in a different fashion, using the multiple logistic equation). The shaded part of the histograms shows how much of the difference in relative risk of each grade is attributable to differences from the administrators in the levels of risk factors. The multiple logistic equation allows an estimate to be made of the effect of a risk factor on CHD death, independent of the effect of all other risk factors. The unshaded part of the histograms shows that approximately $60 \%$ of the grade differences in CHD could not be accounted for by differences in these factors as we assessed them (that is, by a single screening examination).
EFFECT OF SELECTION

Another kind of explanation for these striking CHD differences between the grades would be the effect on mortality of selection into or out of employment. The 'other' grade in particular contains a number of men who obtained their present employment in the civil service after they had become unfit for more physically demanding work. For this reason alone they may be expected to have a higher subsequent mortality. Removing these men from the analysis, however, still leaves a clear gradient of CHD risk between the remaining employment grades. Men in the clerical grade have $3 \cdot 1$ times the risk of those in the administrative grade and 1.5 times the risk of the professional and executive men.

If mortality differences between grades were due to medical factors at recruitment, then they would be expected to show less clearly in men who at entry to the study appeared to be healthy. In Figure 4, CHD mortality rates are shown for men in each grade, classified according to whether at entry into the study they showed any of the following: history of shortness of breath on exertion, or wheeze, angina or pain of possible myocardial infarction on the standard questionnaire, history of treatment for diabetes or vascular disease, or electrocardiographic signs suggestive of ischaemia. The inverse association between grade and CHD mortality is clear and consistent among the $50 \%$ of men with 'disease at entry' to the study (relative risk 3.3), and within each grade, mortality is higher than among the symptom-free men. Among these 

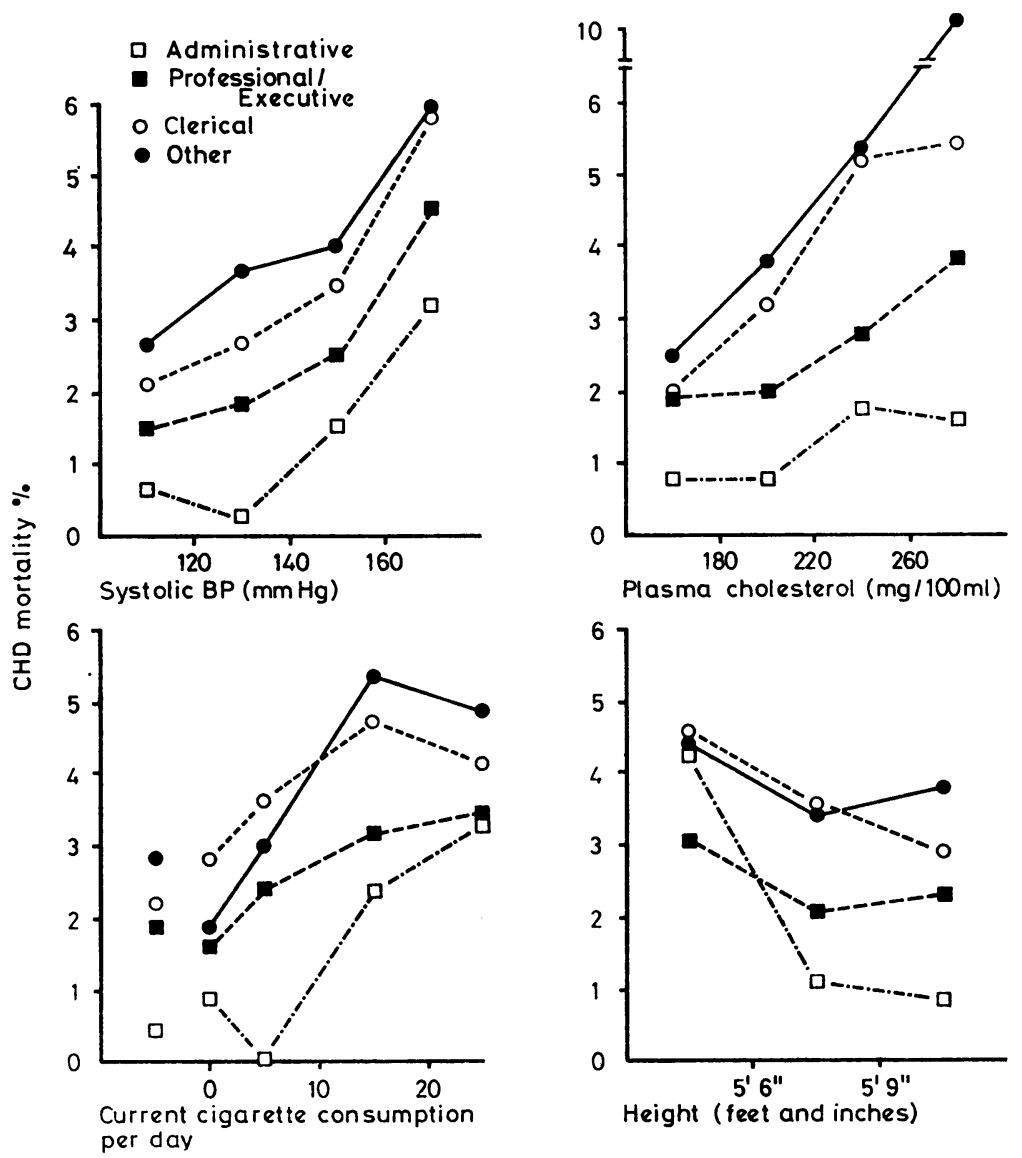

Fig. 2 CHD mortality in seven and a half years by grade and other risk factors (age-adjusted \%). Mortality rates among ex-smokers in the four grades are shown in the left hand section of the smoking chart.

symptom-free men, the stepwise association between grade and mortality is seen for the higher three grades but not for the lowest ('other') grade. This suggests that selective employment of disabled men could not be the major reason for the association of grade with CHD mortality, except perhaps in the lowest grade.

If medical selection were a major factor, it might be expected that the grade differences in mortality would be greater in the early years of follow-up than in the later years. If the sicker men were concentrated in the lower grades at the beginning of the study, then, as they died off, the difference in mortality between the grades should narrow. Figure 5 plots the cumulative probability of CHD death (age-adjusted) for men in each grade over the seven and a half years of follow-up. It can be seen that the mortality differences between the grades have in no way tended to narrow, the relative difference remaining in fact fairly constant. Whatever factors are responsible for the grade differences, their effect persists throughout the follow-up period.

\section{Discussion}

In this study of civil servants, a man's grade of employment was a stronger predictor of his subsequent risk of CHD death than any of the other major coronary risk factors. The mortality difference between the administrative and 'other' grades was in the same direction, but greater in magnitude, than the difference between the CHD mortality of Social Class I and Social Class V reported for England and Wales (Registrar General, 1978). It may be that the grade of a civil servant identifies relevant factors in social class level more accurately than the much cruder classification of national social classes, where each individual class is 


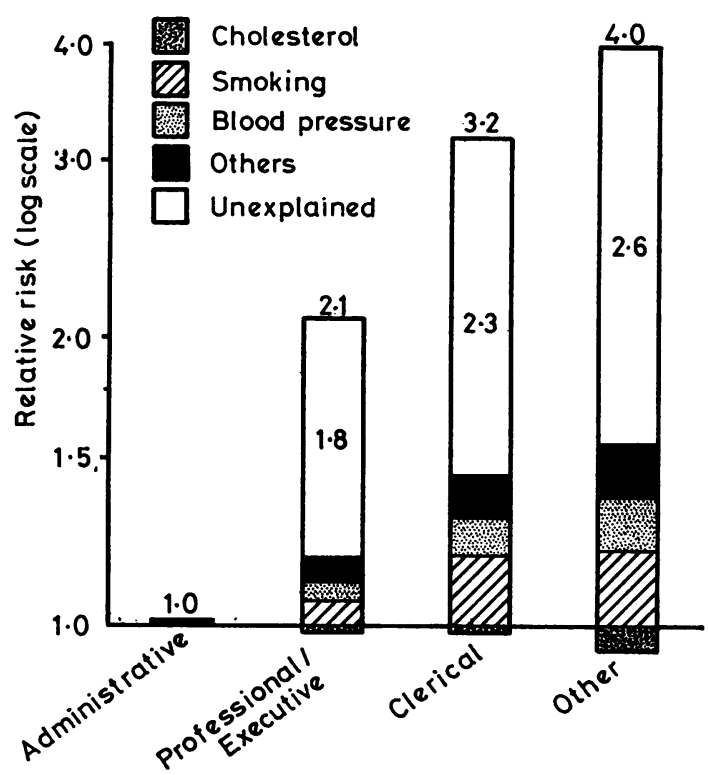

Fig. 3 Relative risk of CHD death in different grades 'explained' by risk factors (age-standardised).

The figures on top of the histograms are the relative risk of CHD death (age-standardised), taking the administrative grade as 1.0. These figures are calculated from the equation and differ slightly from the 'crude' figures.

The figures in the histograms are the relative risk of CHD death in the different grades after the effect of the other risk factors has been taken into account.

undoubtedly very heterogeneous. In that case, the stronger mortality gradient in the civil service would reflect a more accurate classification rather than a truly steeper gradient of risk.

The gradient might be due to self-selection into lower employment grades of men with a higher risk of CHD. Selective recruitment of men with symptoms seems unlikely to have played a major part. There are in general no pre-entry medical examinations for these men; the mortality differential was as strong in the late as in the early period of follow-up: and, except for the lowest grade, a clear mortality gradient was evident even in the men who at entry to the study were apparently symptom-free. Furthermore, most of these middleaged men were career civil servants, and it would have been most remarkable if selective factors operating 20 or more years previously could have predicted current risk so efficiently. It thus seems likely that medical selection, by itself, cannot explain the substantial grade differences in mortality.

The explanation of these differences is not clear.

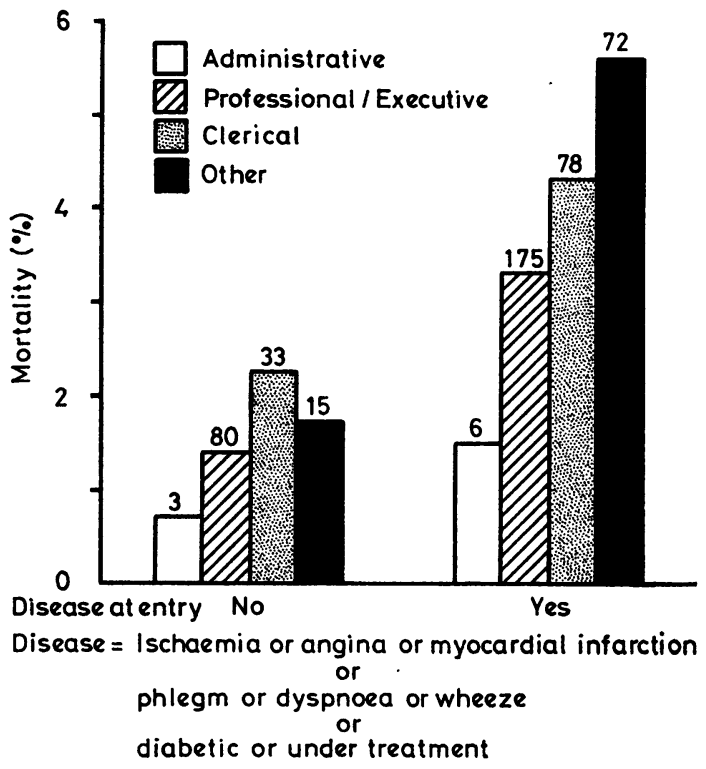

Fig. 4 Seven and a half year CHD mortality by grade and 'disease at entry'.

The figures on top of the histograms are the numbers of CHD deaths.

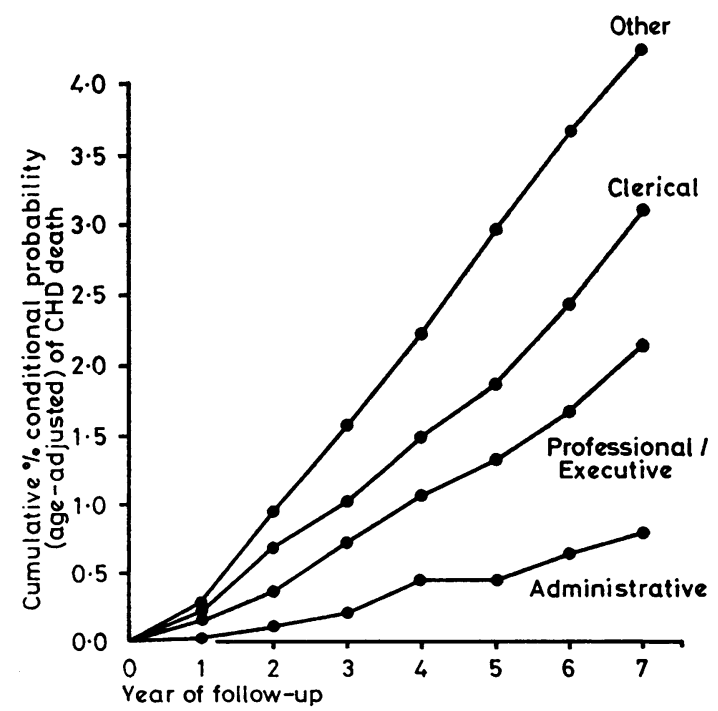

Fig. 5 CHD mortality among total population by year of follow-up.

Smoking is a predictor of CHD death (Reid et al., 1976) and lower grade men smoked more than those in higher grades. However, this difference explained only a small part of the differences in mortality. 
Plasma cholesterol levels were actually higher in the higher grade men. This is consistent with the results of the National Food Survey, which show fat intake to be higher in upper income than in lower income households (National Food Survey, 1973). If such findings are true of the civil servants, as is suggested by our own preliminary dietary surveys, it seems unlikely that the grade difference in mortality could be related to dietary intake of saturated fat. The question of polyunsaturated/ saturated ratio needs further study.

Most men in this study were employed in physically undemanding occupations, so it is necessary to look at leisure-time physical activity for any differences. The rough measure of physical activity used here does show an association with CHD risk (Rose et al., 1977a), and the somewhat higher levels reported by the upper grade men could therefore be a small part of the explanation of their lower CHD risk. Had the present study included a more precise measure of physical activity (Morris et al., 1973), it is possible that a greater part of the grade difference in mortality could have been explained.

Men in the lower grades tended to have higher blood pressure than the upper grade men, in line with previous reports from other populations (Syme, 1974; Dyer, 1976; Holme, 1976). In a separate analysis, we have shown that the greater degree of obesity among the lower grade men does not account for the higher blood pressure. It is of course possible that a greater part of the excess CHD in the lower grades would have been explained if blood pressure measurements had been multiple or more representative of the men's normal conditions of life: for each man we had only one measurement, recorded under standardised conditions.

It appears, then, that the evidence available to us on these men's risk factor status when they entered the study leaves unexplained a large part of the subsequent intergrade differences in death from CHD. This suggests either that there are other major risk factors which we did not measure, or else perhaps that the pattern of risk was already determined by genetic constitution or earlier upbringing. Certainly the independent association between short height and CHD risk is consistent with the operation of some combination of genetic endowment and early nutrition. However, the association between grade and mortality was again largely independent of the differences in height. This suggests the need for continued search for potential aetiological factors in the adult lifestyle or environment of these men. In particular, attention should be paid to better characterisation of diet, including nutrients other than fat, and to psychosocial differences between the grades.

It is to be hoped that from a better understanding of the reasons for social class difference in disease, some means may emerge of protecting groups at such greatly increased risk.

It is a pleasure to acknowledge the continued help of the Civil Service Medical Department. The study was supported by a grant from the Tobacco Research Council.

Reprints from M. G. Marmot, Department of Medical Statistics and Epidemiology, London School of Hygiene and Tropical Medicine, Keppel Street, London WC1E 7HT.

\section{References}

Dyer, A. R., Stamler, J., Shekelle, R. B., and Schoenberger, J. (1976). The relationship of education to blood pressure. Findings on 40000 employed Chicagoans. Circulation, 54, 987-992.

Holme, I., Helgeland, A., Hjermann, I., Lund-Larsen, P. G., and Leren, P. (1976). Coronary risk factors and socioeconomic status. The Oslo study. Lancet, 2, 1396-1398.

Morris, J. N., Chave, S. P. W., Epstein, L., and Sheehan, D. J. (1973). Vigorous exercise in leisure-time and the incidence of coronary heart disease. Lancet, 1, 333-339.

National Food Survey Committee (1973). Ministry of Agriculture, Fisheries and Food. Household Food Consumption and Expenditure 1970 and 1971. HMSO: London.

Registrar General (1978). Occupational Mortality 197072: Decennial Supplement. HMSO: London.

Reid, D. D., Bret, G. Z., Hamilton, P. J. S., Jarrett, R. J., Keen, H., and Rose, G. (1974). Cardiorespiratory disease and diabetes among middle-aged male civil servants. Lancet, 1, 469-473.

Reid, D. D., Hamilton, P. J. S., McCartney, P., Rose, G., Jarrett, R. J., and Keen, H. (1976). Smoking and other risk factors for coronary heart disease in British civil servants. Lancet, 2, 979-984.

Rose, G., and Blackburn, H. (1968). Cardiovascular Survey Methods. wHo: Geneva.

Rose, G., Reid, D. D., Hamilton, P. J. S., McCartney, P., Keen, H., and Jarrett, R. J. (1977a). Myocardial ischaemia, risk factors and death from coronary heart disease. Lancet, 1, 105-109.

Rose, G., McCartney, P., and Reid, D. D. (1977b). Selfadministration of a questionnaire on chest pain and intermittent claudication. British Journal of Preventive and Social Medicine, 31, 42-48.

Syme, S. L., Oakes, T. W., Friedman, G. D. et al. (1974). Social class and racial differences in blood pressure. American Journal of Public Health, 64, 619-620.

World Health Organisation (1967). International Classification of Diseases, 8th revision. WHO: Geneva. 